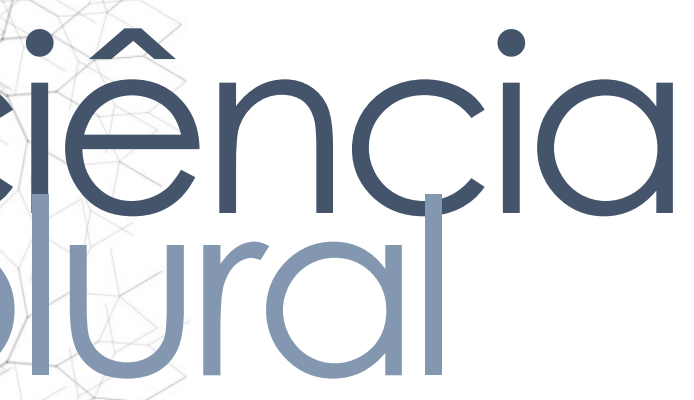

\title{
GINCANA EDUCATIVA - COMO SALVAR UMA VIDA: ESTRATÉGIA SOBRE PRIMEIROS SOCORROS PARA ADOLESCENTES
}

Educative Gymkhana -- How to save a life: strategy on first aid for adolescents

Gincana Educativa - Cómo salvar una vida: estrategia de primeros auxilios para adolescentes

Maria Aparecida Fernandes Cardoso • Acadêmica de Enfermagem pela Universidade Estadual Vale do Acaraú (UVA) • E-mail: aparecidafernandes31@gmail.com

Jefferson Dantas da Costa $\bullet$ Acadêmico de Enfermagem pela Universidade Estadual Vale do Acaraú (UVA) • E-mail: jeffersondantas3840@gmail.com

José Leonardo Alves de Sousa Filho • Enfermeiro pela Universidade Estadual Vale do Acaraú (UVA) • E-mail: leorick95@gmail.com

Keila Maria de Azevedo Ponte Marques • Enfermeira • Doutora em Cuidados Clínicos em Enfermagem e Saúde pela Universidade Estadual do Ceará (UECE) • Docente do Curso de Graduação em Enfermagem da UVA • E-mail: keilinhaponte@hotmail.com

Autora correspondente:

Maria Aparecida Fernandes Cardoso • E-mail: aparecidafernandes31@gmail.com 


\section{ciêncíncia
puúl}

\section{RESUMO}

Introdução: Verifica-se que a educação em saúde é uma estratégia de ensino e aprendizagem com objetivo de melhorar a qualidade de vida e de saúde da população. Objetivo: Descrever uma estratégia educativa sobre primeiros socorros para adolescentes. Metodologia: Trata-se de uma pesquisa ação realizada em maio de 2019 com 27 adolescentes, estudantes de uma escola situada na cidade de Itapajé, Ceará. A pesquisa seguiu as seguintes etapas: Iniciação do Projeto de Pesquisa Ação; A Definição da Estrutura Conceitual Teórica; Definição do Contexto e Propósito da Pesquisa; e Coleta de dados, que se deu em quatro momentos, por meio de um Instrumento de Coleta de Dados semiestruturado e aplicação da Gincana Educativa Como salvar uma vida. Pesquisa aprovada pelo Comitê de Ética em Pesquisa da Universidade Estadual Vale do Acaraú com número 3.241.797. Resultados: A Gincana foi organizada em seis etapas: Torta na cara, Jogo de Cooperação, Desafio, Resistência física, Quiz e Demonstração, buscando deixar o momento descontraído, dinâmico, competitivo e de aprendizado. Verificou-se que os participantes tiveram interesse na aprendizagem sobre primeiros socorros, principalmente quando acompanhadas pela utilização de tecnologias educativas. Conclusões: A gincana contribuiu no aprendizado sobre primeiros socorros dos escolares, o que lhes permitiu prevenir possíveis agravos em saúde, além de torná-los possíveis disseminadores de conhecimento.

Palavras-Chave: Primeiros Socorros; Educação em saúde; Adolescente.

\section{ABSTRACT}

Introduction: It appears that health education is a teaching and learning strategy aimed at improving the quality of life and health of the population. Objective: Describe an educative strategy on first aid for adolescents. Methodology: This is an action research carried out in May 2019 with 27 adolescents, students from a school located in the city of Itapajé, Ceará. The research followed thesteps: Initiation of the Action Research Project; The Definition of Theoretical Conceptual Framework; Definition of the Context and Purpose of the Research; and data collection, which took place in four moments, using a semi-structured Data Collection Instrument and application of the Educational Gymkhana - How to save a life. Research approved by the Research Ethics Committee of the State University Vale do Acaraú with number 3,241,797. Results: The Gymkhana was organized in six stages: Pie in the face, Cooperation Game, Challenge, Physical resistance, Quiz and Demo, seeking to leave the moment relaxed, dynamic, competitive and learning. It was found that the participants had interested in learning about first aid, mainly when accompanied by the use of educative Technologies. Conclusions: The gymkhana contributed to the tudents' first aid learning, which allowed them to prevent possible health problems, addition to making them possible disseminators of knowledge.

ywords: First Aid; Health Education; Adolescent. 


\section{RESUMEN}

Introducción: Verifica que la educación para la salud es una estrategia de enseñanza y aprendizaje dirigida a mejorar la calidad de vida y la salud de la población. Objetivo: Describir una estrategia educativa sobre primeros auxilios para adolescentes. Metodología: Se trata de una investigación-acción realizada en mayo de 2019 con 27 adolescentes, estudiantes de una escuela ubicada en la ciudad de Itapajé, Ceará. La investigación siguió los siguientes pasos: Inicio del proyecto de investigación-acción; La definición de marco conceptual teórico; Definición del contexto y propósito de la investigación; y Recopilación de datos, que tuvo lugar en cuatro momentos, a través de un Instrumento de Recolección de Datos semi-estructurado y aplicación de la Gymkhana Educativa - Cómo salvar una vida. Investigación aprobada por el Comité de Ética en Investigación de la Universidad Estatal Vale do Acaraú con el número 3.241.797. Resultados: La Gymkhana se organizó en seis etapas: Torta en la cara, Juego de cooperación, Desafío, Resistencia física, Quiz y Demostración, buscando salir del momento relajado, dinámico, competitivo y aprendiendo. Se encontró que los participantes tenían interesados en aprender sobre primeros auxilios, especialmente cuando se acompañan del uso de tecnologías educativas. Conclusiones: La gymkana contribuyó al aprendizaje de los estudiantes en primeros auxilios, lo que les permitió prevenir posibles problemas de salud, además de hacerlos posibles divulgadores de conocimientos.

Palabras clave: Primeros Auxilios; Educación en Salud; Adolescente. 


\section{Introdução}

Definem-se como primeiros socorros as avaliações e intervenções realizadas com o objetivo de ajudar pessoas que estejam em situação de emergência em saúde, na qual, mesmo aquele que não seja profissional, possa realizar a assistência inicial à vítima com objetivo de aumentar a probabilidade de sobrevivência e preservar a vida até a chegada do serviço de atendimento especializado ${ }^{1}$. Assim, é fundamental que todos estejam preparados para prestar cuidados iniciais em situações de risco de vida, todavia, a maior parte da população não sabe iniciar os primeiros socorros em condições ideais².

É necessário esclarecer e treinar a população para o atendimento de situações de emergência que envolvam, por exemplo, a parada cardíaca, evitando a paralisia do socorrista no momento de decidir qual o próximo passo a seguir ${ }^{3}$.

Estudos apontam que o ensino sobre prevenção de acidentes e primeiros socorros é mais presente em universidades e para os profissionais da saúde, no entanto, verifica-se a necessidade dessa temática ser abordada ao público leigo. Nesse ínterim, a infância e adolescência são fases decisivas na construção de hábitos e atitudes. Neste período, pode-se desenvolver um trabalho sistematizado e contínuo que promova a este grupo comportamentos favoráveis à saúde ${ }^{4,5}$.

No que se refere especificamente a adolescência, essa fase configura-se como uma das mais importantes no desenvolvimento humano, desse modo, acolher suas necessidades podem fornecer formas de cuidados e favorecer o suporte social e emocional, contribuindo para o fortalecimento de recursos individuais no enfrentamento das adversidades existentes na idade ${ }^{6,7}$.

Assim, o público adolescente necessita de uma atenção especial, pois estudos mostram que em relação à saúde dos adolescentes, há um diferencial que expressa a ua vulnerabilidade frente às diferentes formas de violência e à crescente incidência mortalidade, evidenciadas especialmente pelas causas externas, como as agressões s acidentes de transporte, entre outras ${ }^{8}$. 
Nessa perspectiva, verifica-se que a educação em saúde é uma estratégia de ensino e aprendizagem com objetivo de melhorar a qualidade de vida e de saúde da população. Ademais, vale salientar que os recursos educativos permitem a reflexão e o exercício do protagonismo do participante acerca da temática abordada sendo, assim, ferramenta importante para realização de mudança no que diz respeito aos mitos e práticas populares sobre primeiros socorros ${ }^{9}$.

Assim, este estudo parte do pressuposto de que existe despreparo do público leigo, gerando imperícia dos mesmos, devido principalmente à falta de informações quanto a temática abordada nesta pesquisa. Desse modo, o estudo é relevante por estar intrinsicamente ligado a uma das atribuições mais importantes para o enfermeiro na atualidade, a educação em saúde. Assim, qualificar o público leigo a respeito de noções básicas sobre primeiros socorros pode gerar um grande impacto na formação cientifica, técnica e humana de jovens adolescentes.

Logo, estudos referentes as estratégias educativas sobre os primeiros socorros são relevantes para a enfermagem uma vez que podem contribuir com as intervenções educativas realizadas por essa categoria profissional no ambiente escolar ${ }^{10}$.

Com base no exposto, o objetivo da pesquisa é descrever uma estratégia educativa sobre primeiros socorros para adolescentes.

\section{Metodologia}

Trata-se de uma pesquisa ação, no qual há uma ação deliberada de transformação da realidade, tendo como objetivo de transformar a realidade e produzir conhecimentos relativos à essas transformações ${ }^{11}$. Além disso, as descrições presentes nas pesquisas ultrapassam a identificação pura e simples dos dados. As informações geram novos pontos de vista acerca da situação e do problema em estudo, fato que aproxima tal modelo das pesquisas de caráter exploratório ${ }^{12}$.

O estudo foi realizado em maio de 2019, por meio de três encontros com 27 plescentes leigos estudantes das três séries do ensino médio da escola Patronato São (PSJ) do município de Itapajé-Ceará. A seleção da amostra teve como critérios de 
inclusão: ser estudante das três séries do ensino médio e ser do período da manhã. E de exclusão: Estudantes do ensino médio que estavam suspensos, acometidos por doença que os privaram de participar, viajando para outra localidade, faltosos e que precisaram se ausentar para realizar uma avaliação semestral.

O planejamento da pesquisa seguiu as seguintes etapas da pesquisa-ação: Iniciação do Projeto de Pesquisa Ação; A Definição da Estrutura Conceitual Teórica; Definição do Contexto e Propósito da Pesquisa; e a Coleta de dados.

Na etapa de Iniciação do Projeto de Pesquisa Ação, os adolescentes em fase escolar são mais acessíveis a novos saberes e competências intelectuais, assim, a capacitação sobre primeiros socorros com os mesmos é de grande importância social, visto que, o conjunto de conhecimentos e técnicas em primeiros socorros podem ser decisivos em uma situação de urgência. Para isso, é necessário o uso de estratégias educativas inovadoras para o ensino sobre primeiros socorros com adolescentes, por ser ferramenta eficiente para promoção da saúde e prevenção de agravos.

Quanto a Definição da Estrutura Conceitual Teórica, foi realizado uma pesquisa bibliográfica sobre estratégias de educação em saúde sobre primeiros socorros para adolescentes leigos. Identificou-se vulnerabilidade e incipiência de produção científica na área, considerando dessa forma, de fundamental importância este estudo.

Na Definição do Contexto e Propósito da Pesquisa, aprofundou-se a leitura sobre ações de promoção da saúde com adolescentes para realizar o mapeamento na literatura das principais atividades de promoção da saúde realizadas com adolescentes foi definida a seguinte questão norteadora: qual a contribuição de uma estratégia educativa sobre primeiros socorros para adolescente leigos?

No que se refere a coleta de dados, esta ocorreu em quatro momentos:

Primeiro momento: Ocorreu o primeiro encontro com os adolescentes com perfil para o estudo, onde foram concentrados na biblioteca da escola. Na ocasião ocorreu o clarecimento sobre os objetivos e a metodologia da pesquisa para os mesmos, tendo o convidados a participar da pesquisa e assinar o Termo de Assentimento. Os que m menores de 18 anos levaram ao seu domicilio o Termo de Consentimento Livre clarecido que foi apresentado aos seus respectivos pais, cuidadores e responsáveis 
solicitando a permissão para a participação no estudo. Estes documentos foram elaborados em duas vias, sendo uma para o participante e outra para o pesquisador.

Foi pactuado um segundo encontro com os participantes, para entrega dos termos assinados e preenchimento do Instrumento de Coleta de Dados (ICD) semiestruturado, com o objetivo de identificar o perfil socioeconômico dos adolescentes, com informações sobre idade, sexo, estado civil, e com quem residiam. Também havia perguntas de conhecimento prévio sobre primeiros socorros e as possíveis vivências, sendo indagados com as respectivas perguntas: $O$ que você sabe sobre primeiros socorros? Você já passou ou presenciou alguma situação de emergência (ex.: acidentes, ferimentos por faca ou arma de fogo, mal-estar, desmaio ou convulsão). Foi identificado também, o interesse dos adolescentes a respeito da temática de primeiros socorros. No final do ICD foi sugerido opções para que os mesmos escolhessem o tipo de intervenção que queriam para a abordagem da temática, onde as opções foram: vídeo, palestra, gincana, panfleto e peça teatral.

Segundo Momento: Ocorreu a análise dos dados coletados no primeiro momento, planejamento e elaboração da estratégia educativa a partir do perfil dos participantes, o interesse e a contagem de votos na escolha da intervenção.

A estratégia foi denominada: Gincana educativa - Como Salvar uma Vida. Esta etapa está descrita detalhadamente nos resultados da pesquisa.

Terceiro Momento: Ocorreu o terceiro encontro com a efetivação da Gincana educativa - Como Salvar uma Vida com os adolescentes. No final do encontro foi aplicado novamente o ICD semiestruturado. Após o término, foi solicitado que os mesmos avaliassem a intervenção e ao final foi divulgado a equipe vencedora do desafio, onde todos foram premiados como forma de motivação e agradecimento.

Quarto Momento: A análise dos dados do ICD foi realizada com auxílio do Microsoft Excel 2016, para organização e tabulação dos mesmos. Em seguida as informações, a respeito de todos os momentos e respostas das questões feitas, ssaram por um processo de comparação dos resultados prévios e posteriores a ervenção, com a finalidade de identificar se ocorreu uma soma de conhecimentos a ir da estratégia aplicada. A elaboração dos dados e achados, bem como a discussão 
a partir da literatura cientifica, foram efetivados e podem ser observados com mais detalhes nos resultados.

Este estudo obedeceu aos preceitos da ética em pesquisa seres humanos de acordo com a Resolução de No 466/2012 do Conselho Nacional de Saúde, a qual contém diretrizes e normas regulamentadoras de pesquisas que envolvem seres humanos ${ }^{13}$. Sendo assim, a pesquisa foi aprovada pelo Comitê de Ética em Pesquisa da Universidade Estadual Vale do Acaraú com parecer número 3.241.797.

\section{Resultados e Discussão}

Os participantes foram 27 adolescentes, sendo que a idade variou de 15 a 18 anos, sendo a maioria com 15 anos, 44,45\% a maior parte foi do sexo masculino 66,66\%, solteiros $81,49 \%$ e que residiam com os pais $77,78 \%$, os mesmos cursavam o ensino médio na escola Patronato São José na cidade de Itapagé, Ceará.

Em relação ao interesse quanto ao tema sobre primeiros socorros, 25 dos estudantes optaram por ter mais acesso ao conteúdo, enquanto apenas dois não estavam interessados em um segundo momento. Essa estatística é importante para a percepção de que o público adolescente tem interesse em desenvolver habilidades e conhecimentos sobre primeiros socorros.

Sendo assim, dão a devida importância para a temática e estão dispostas a tentar ajudar pessoas que sofreram de algum agravo a saúde, porém não possuem alguém que os embase teoricamente e tecnicamente. Contudo, é preciso considerar que ainda existe uma minoria que acha desnecessário esses conhecimentos, e que devem ser propriedade apenas dos profissionais de saúde e acadêmicos da área. Assim, é algo que podemos levar a reflexão a respeito do valor do prestar socorro, ajudar e cuidar dos doentes, feridos e necessitados na atualidade.

O principal obstáculo ao atendimento inicial pelos leigos em situações de mergência parece ser a falta de orientação e capacitação, visto que eles reconhecem papel e mostraram-se interessados em aprender as técnicas do Suporte Básico de da. Assim, medidas de capacitação provavelmente teriam grande adesão e 
repercussão, tornando o leigo capacitado para atuar no atendimento inicial de emergências em ambientes extra - hospitalares ${ }^{14}$.

Quanto ao conhecimento prévio sobre primeiros socorros dos adolescentes, 18,5\% (5) não sabiam nada e 81,5\% (22) afirmaram ter algum conhecimento prévio. No entanto, este conhecimento prévio era superficial e algumas vezes equivocado. No que se refere às vivências de alguma situação de emergência, 59,25\%(16) já experimentaram situações de acidentes, enquanto 40,75\%(11) nunca tiveram.

Em um estudo realizado em Cuité-Paraíba, na qual foi optado pela utilização de uma oficina educativa e adotado um pré-teste e um pós-teste de 14 itens, foi possível observar a evolução do público jovem no que diz respeito a aprendizagem sobre primeiros socorros. Sendo assim é possível analisar que existe déficit de conhecimento sobre a temática e que é preciso realizar uma abordagem inicial sobre o assunto desde a idade escolar ${ }^{15-16}$.

A pesquisa mostrou a fragilidade no conhecimento dos adolescentes sobre primeiros socorros, necessitando de instrução a respeito da temática. Apresentou que o público adolescente está exposto a inúmeras causas externas que podem levá-los a agravos significativos e revelou que a maioria deles estiveram envolvidos em circunstancias de perigo real, e que em grande parte dos casos não souberam como agir e nem ao menos acionar o socorro especializado.

Dessa forma, é necessário salientar acerca da importância do adolescente como multiplicador de conhecimento, sendo assim, utiliza-se a metodologia de educação entre pares, a qual consiste em um processo de ensino e de aprendizagem em que adolescentes são preparados para atuar em ações e em atividades com e para outros (as) adolescentes e jovens ${ }^{17}$.

Na escolha da estratégia educativa, observou-se que após a análise dos dados oletados, a forma que obteve mais votos foi a gincana educativa, com doze votos, nforme se apresenta na Tabela 1: 
Tabela 1 -Distribuição dos participantes de acordo com a escolha da estratégia educativa sobre primeiros socorros. Itapajé-CE, 2019.

\begin{tabular}{ccc}
\hline TIPOS DE & $\mathbf{N}$ & $\%$ \\
ESTRATÉGIA & 12 & 44,4 \\
GINCANA & 7 & 25,9 \\
PALESTRA & 3 & 11,1 \\
VÍDEO & 3 & 11,1 \\
TEATRO & 2 & 7,5 \\
SEM INTERESSE & $\mathbf{2 7}$ & 100 \\
\hline TOTAL & & \\
\hline
\end{tabular}

Fonte: Dados da Pesquisa, 2019.

Com base na votação do modelo da abordagem, é nítido que a maior parte do público adolescente, está mais propenso a metodologias de ensino mais práticas, interativas e dinâmicas, que deixem o conteúdo mais lúdico e ativo, juntando a teoria e prática. Sendo assim, os pesquisadores elaboraram a intervenção baseada na forma de maior interesse, visando atrair o público alvo, a fim de, somar os conteúdos de maneira simples e lúdica para melhor absorção de conhecimento, conforme proposto pela pesquisa-ação.

Vale ressaltar que situações de emergências médicas ocorrem nos mais variados locais, que incluem residências, locais de práticas esportivas, shoppings, entre outros, ambientes estes que normalmente o público jovem frequenta. Sendo assim, a escola tem representado um importante local para o encontro entre saúde e educação abrigando principalmente atividades de educação em saúde e promoção da saúde 18 . Além disso, por ser o ambiente em que se encontra a maior parte do público adolescente, são laboratórios ideais para educação em saúde sobre técnicas básicas que compõem o Suporte Básico de Vida99.

A criação da gincana foi feita visando deixar o momento mais descontraído, dinâmico e em clima de aprendizado e participação. Os estudantes foram divididos em equipes conforme as séries que estavam cursando, no qual resultou em três equipes, representadas pelo primeiro, segundo e terceiro ano do sino médio.

Cada etapa possuía determinadas tarefas e atividades a serem cumpridas, e a aioria delas possuíam uma pontuação específica, a fim de definir uma equipe 
vencedora ao final da intervenção, estimulando o espírito de competição saudável entre as equipes para que se empenhassem na execução das atividades. O momento foi divido em seis etapas, conforme está apresentado no quadro 1, sendo que cada etapa exigia um conhecimento básico a respeito do tema.

Quadro 1 - Etapas da Gincana Educativa - Como salvar uma vida. Itapajé-CE, 2019.

\begin{tabular}{|c|c|c|}
\hline Etapas & Objetivo & Realização \\
\hline 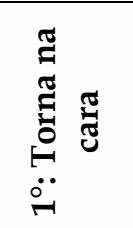 & $\begin{array}{l}\text { Gerar discussões e repasses sobre condutas } \\
\text { ideais frente a situações que exigem } \\
\text { habilidades para prevenção de acidentes e } \\
\text { realização de primeiros socorros. }\end{array}$ & $\begin{array}{l}\text { As equipes foram distribuídas em filas e dois } \\
\text { adversários se enfrentavam em um rodízio de } \\
\text { perguntas, ao pontuar respondendo } \\
\text { corretamente, a equipe vencedora acertava uma } \\
\text { torta de espuma na face dos adversários. }\end{array}$ \\
\hline 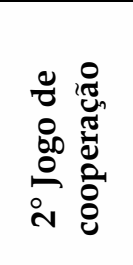 & $\begin{array}{l}\text { Estimular o trabalho em equipe e a importância } \\
\text { da colaboração para o alcance dos objetivos. } \\
\text { Desenvolver conhecimentos básicos sobre } \\
\text { cuidados a uma pessoa que desmaia. }\end{array}$ & $\begin{array}{l}\text { Os participantes deveriam erguer uma pirâmide } \\
\text { de copos descartáveis o mais alto que pudessem, } \\
\text { dentro de um minuto, usando apenas um dos } \\
\text { braços. } \\
\text { Encenar um atendimento a uma vítima de } \\
\text { vertigem evoluindo para desmaio. }\end{array}$ \\
\hline 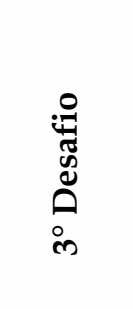 & $\begin{array}{l}\text { Conhecimento teórico deve estar ligado } \\
\text { também ao preparo físico, emocional e mental. } \\
\text { - Instigar habilidades de atendimento básico a } \\
\text { uma pessoa em convulsão. }\end{array}$ & $\begin{array}{l}\text { Os participantes precisavam estourar a máximo } \\
\text { de bolas de assopro, em um minuto, usando } \\
\text { apenas o ar da inspiração, testando sua } \\
\text { capacidade de expansão pulmonar, fôlego e } \\
\text { resistência. } \\
\text { Simulação de primeiros socorros frente a uma } \\
\text { convulsão. }\end{array}$ \\
\hline 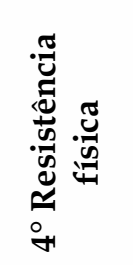 & $\begin{array}{l}\text { Reconhecer quando uma ação pode levá-lo a } \\
\text { um desgaste desnecessário, que dependendo } \\
\text { da situação pode colocar em risco a sua } \\
\text { segurança. } \\
\text { Ensino-aprendizagem sobre a abordagem } \\
\text { inicial a uma vítima de engasgo. }\end{array}$ & $\begin{array}{l}\text { Os participantes deveriam sustentar o peso de } \\
\text { outro colega sobre suas costas com o apoio } \\
\text { apenas de suas pernas, a dupla que resistisse até } \\
\text { o final seria a vencedora. } \\
\text { Encenar um atendimento a uma vítima de } \\
\text { engasgo. }\end{array}$ \\
\hline $\begin{array}{l}\text { Na } \\
\text { ă } \\
\text { in }\end{array}$ & $\begin{array}{l}\text { Desenvolver técnicas e conhecimentos a } \\
\text { respeito de queimaduras, traumas abertos e } \\
\text { fechados, e o que não fazer nesses casos. }\end{array}$ & $\begin{array}{l}\text { Foram lançadas perguntas a respeito da } \\
\text { temática, a equipe que chegasse mais próximo } \\
\text { da conduta ideal pontuava. }\end{array}$ \\
\hline ف & $\begin{array}{l}\text { Criar um momento divertido, dinâmico e } \\
\text { interativo entre os pesquisadores e os escolares. } \\
\text { Desenvolver competências necessárias para } \\
\text { manejo de uma situação de parada } \\
\text { cardiorrespiratória }\end{array}$ & $\begin{array}{l}\text { Foi lhes dado um pacote de bolachas "cream } \\
\text { cracker" para cada grupo, a equipe que } \\
\text { conseguisse acabar o pacote primeiro venceria a } \\
\text { disputa. } \\
\text { Encenar um atendimento a uma vítima em } \\
\text { parada cardiorrespiratória. }\end{array}$ \\
\hline
\end{tabular}

onte: Dados da Pesquisa, 2019.

Com o término e a conclusão da última fase da dinâmica, os pesquisadores correram a respeito das pontuações, e qual equipe tinha conseguido mais pontos, s a análise do momento, da participação empenho e conhecimento técnico prático, 
foi decidido qual equipe seria a campeã da gincana a partir das pontuações conforme descreve a tabela 2.

Tabela 2 - Pontuações em cada etapa da estratégia educativa e os resultados de cada equipe nas respectivas fases. Itapajé-CE, 2019.

\begin{tabular}{|c|c|c|c|c|c|}
\hline \multicolumn{2}{|c|}{ FASES DA GINCANA } & $\begin{array}{l}\text { PONTUAÇÃO } \\
\text { DA FASE }\end{array}$ & $\underset{1}{\text { Equipe }}$ & $\underset{2}{\text { Equipe }}$ & $\underset{3}{\text { Equipe }}$ \\
\hline \multicolumn{2}{|c|}{$\begin{array}{c}\text { Avaliar nome, grito de guerra e } \\
\text { animação }\end{array}$} & 50 & 0 & 50 & 0 \\
\hline $\mathbf{1}^{\mathrm{a}}$ Etapa & TORTA NA CARA & 50 & 40 & 30 & 30 \\
\hline $2^{a}$ Etapa & COOPERAÇÃO & $40-20$ & 40 & 20 & 30 \\
\hline $3^{\mathbf{a}}$ Etapa & DESAFIO & $40-20$ & 20 & 40 & 30 \\
\hline $4^{\mathrm{a}}$ Etapa & RESISTENCIA FÍSICA & $40-20$ & 30 & 40 & 20 \\
\hline $5^{a}$ Etapa & QUIZ & $40-20$ & 40 & 30 & 20 \\
\hline $6^{\mathrm{a}}$ Etapa & DEMONSTRAÇÃO & - & \multicolumn{3}{|c|}{ Sem pontuação } \\
\hline $\begin{array}{c}\text { Equipe } \\
\text { Vencedora }\end{array}$ & EQUIPE 2 & Total & 170 & 210 & 130 \\
\hline
\end{tabular}

Fonte: Dados da Pesquisa, 2019.

Após as análise, foi decidido que a equipe que mais se esforçou e manteve sempre uma postura de empolgação e aprendizado foi a equipe 2 , que apresentou uma maior aptidão em conhecimento e técnica nas simulações e dinâmicas. $\mathrm{O}$ momento de premiação foi muito celebrado e comemorado pela equipe vencedora, todavia, todos os participantes receberam um chocolate pela participação e empenho nas atividades propostas.

Entende-se que as técnicas de primeiros socorros precisam ser trabalhadas nos espaços educacionais e os educadores devem buscar métodos através dos quais as crianças e adolescentes possam aprender de forma simples e divertida, saindo da rotina dos conteúdos teóricos, participando de brincadeiras e simulações que lhes possibilitem conhecer as primeiras noções de prevenção de acidentes e primeiros socorros, e consequentemente saber o que fazer em situações emergenciais. Essas stratégias são fundamentais para a promoção da saúde dos adolescentes, incentivando comportamentos saudáveis ${ }^{7,20}$.

Após a intervenção, os adolescentes foram convidados a avaliar a estratégia ucacional de primeiros socorros utilizada como intervenção para o aprendizado dos 
mesmo a respeito da temática. Acerca da contribuição da tecnologia, em relação aos pontos positivos, obteve-se respostas como:

"Muito sobre primeiros socorros que antes desconhecia e agora eu sei como agir diante de algum acidente." (A19)

"A dinâmica foi amplamente descontraída e informativa. De maneira que os conhecimentos anteriormente confusos, foram bem esclarecidos." (A09)

“Tudo. Todo o aprendizado foi essencial tanto para exercer os cuidados a quem necessita, quanto a escolha da nossa futura profissão." (A02)

É certo que os acidentes e agravos em saúde podem levar a uma situação de urgência e emergência, dessa forma, um ponto é fundamental: o acesso à informação por meio de educação em saúde implica em resultados significativos na prevenção e na minimização de complicações decorrentes de intervenções inadequadas ${ }^{4}$. Sendo assim, é perceptível a importância de capacitar a população leiga e principalmente adolescentes acerca dessa temática, gerando formas de diminuir os danos prejudiciais ao indivíduo que está em situação de risco.

Ao serem perguntados o que poderia melhorar, eles disseram que deveria trazer mais equipamentos, ter mais tempo e outros acharam perfeito:

"Não muita coisa, só trazer mais equipamentos." (A03)

"Ter mais tempo para explicar as coisas." (A01)

"Acho que não precisa melhorar, está tudo perfeito." (A14)

Verificou-se que os participantes tinham interesse na aprendizagem sobre primeiros socorros, principalmente quando acompanhadas pela utilização de tecnologias educativas. Assim, reveste-se de particular relevância a incorporação de uma abordagem rotineira de primeiros socorros na grade curricular em escolas úblicas e privadas de todo o país, visto o grande potencial de aprendizagem nesta ixa etária e a capacidade de ser protagonista em discutir e ensinar aos amigos e niliares o que é aprendido em sala de aula ${ }^{19}$. 
Quanto ao aprendizado com a estratégia educativa, eles afirmaram:

"Que todo mundo pode aprender primeiros socorros e que é necessário." (A8)

"Aprendi como posso utilizar meus conhecimentos para ajudar quem estiver precisando." (A10)

"Muito sobre primeiros socorros que antes desconhecia e agora eu sei como agir diante de algum acidente." (A19)

As avaliações em geral foram bastante positivas e motivadoras, mostrando a importância e relevância do repasse desses conteúdos de forma dinâmica, explicativa e interativa, que por meio de momentos como esse a população pode ser beneficiada e emponderada com esses conhecimentos.

Assim, não menos importante que essa consideração, entretanto, é a possibilidade do desenvolvimento de habilidades de educador e facilitador do enfermeiro frente às necessidades de educação em saúde sobre primeiros socorros. Soma-se a isso, fatores como a troca de saberes entre os acadêmicos e os adolescentes escolares durante o processo de ensino aprendizagem que, dessa forma, fortalece a capacitação adequada sobre a temática ${ }^{21}$.

Como fator limitante da pesquisa, destaca-se o curto período de tempo que os participantes tiveram para relatar qual a contribuição da tecnologia.

\section{Conclusões}

Neste estudo foi possível identificar que a Gincana Educativa: Como salvar uma vida contribuiu de forma significativa no aprendizado dos adolescentes sobre primeiros socorros, pois, os mesmos foram beneficiados de maneira cientifica, técnica humana, onde vivenciaram a oportunidade de tirar suas dúvidas, desmitificar saberes incorretos e serem treinados e capacitados a servir, ajudar e prestar socorro se necessário, de maneira simples, porém efetiva. Dessa forma, proporcionando uma rande diferença na vida de um indivíduo acometido com injúrias a sua estabilidade blógica. 
No decorrer da intervenção os adolescentes mantiveram-se atentos e participativos, possuíam diversas dúvidas a respeito da temática e estavam dispostos a aprender e colaborar com o momento proposto. Vale destacar, que a enfermagem pode ofertar essa gama de conteúdos para habilitar, instruir e qualificar o público leigo quanto a esses assuntos de grande importância, visto que, um dos principais requisitos para o enfermeiro na atualidade é a sua capacidade de promoção da saúde e prevenção de agravos.

Novos estudos devem ser realizados na área visando capacitar o público leigo em todos os âmbitos, adotando estratégias com dinamismo e objetividade, com o intuito de atrair e capacitar, por meio de uma educação continuada. Por conseguinte, é esperado que esta tecnologia educativa possa ser uma opção de estratégia de educação em saúde junto a adolescentes.

\section{Referências}

1. Singletary EM, Charlton NP, Epstein JL, Ferguson JD, Jensen JL, MacPherson AI, et al. First Aid: 2015 American Heart Association and American Red Cross Guidelines Update for First Aid. Circulation [Internet]. 2015 [acesso em 2019 Set 25]; 132 (18 Suppl. 2):574-89. Disponível em:

https:/ / www.ahajournals.org/doi/full/10.1161/CIR.0000000000000269.

2. Gonzalez MM, Timerman S, Oliveira RG, Polastri TF, Canesin MF, Schimidt A, et al. I Diretriz de Ressuscitação Cardiopulmonar e Cuidados Cardiovasculares de Emergência da Sociedade Brasileira de Cardiologia. Arq. Bras. Cardio. [Internet]. 2013 [acesso em 2019 Jul 22]; 101 (2 supl. 3): 1-221. Disponível em: http:/ / www.scielo.br/pdf/abc/v100n2/v100n2a01.pdf.

3. Lima LLN, Reinaldo Junior N. Brigada Estudantil de Prevenção de Acidentes e Primeiros Socorros em Palmas (TO). Revista brasileira de educação médica [Internet]. 2016 [acesso em 2019 Ago 21]; 40(2):310-313. Disponível em: http:/ / www.scielo.br/pdf/rbem/v40n2/1981-5271-rbem-40-2-0310.pdf.

Pereira KC, Paulino JR, Saltarelli RMF, Carvalho AMP, Santos RB, Silveira $\mathrm{VL}$, et al. A construção de conhecimentos sobre prevenção de acidentes e primeiros corros por parte do público leigo. Revista de Enfermagem do Centro Oeste Mineiro ternet]. 2015 [acesso em 2019 Out 10]; 5(1):1478-1485. Disponível em: tps:/ / docs.google.com/viewerng/viewer?url=http:// www.seer.ufsj.edu.br/index p/recom/article/viewFile/456/837. 
5. Sales CCF, Meschial WC, Oliveira MLF. Construção de oficinas pedagógicas para prevenção das intoxicações infantis. Arq. Cienc. Saúde UNIPAR [Internet]. 2018 [acesso em 2019 Set 24]; 22(1):17-22, Disponível em:

https:/ / revistas.unipar.br/index.php/saude/article/view/6221/3556.

6. Silveira RE, Reis NA, Santos AS, Borges MR, Soares SM. Oficinas com adolescentes na escola: uma estratégia de educação em saúde. Nursing (São Paulo) [Internet]. 2011[acesso em 2019 Dez 18];14(157):334-8. Disponível em:

https:/ / www.scielo.br/scielo.php?script=sci_nlinks\&pid=S0080623420150005007410 0001\&lng=en

7. Costa RF, Zeitoune RCG, Queiroz MVO, García CIG, García MJR. Redes de apoio ao adolescente no contexto do cuidado à saúde: interface entre saúde, família e educação. Revista da Escola de Enfermagem da USP [Internet]. 2015 [acesso em 2019 Set 24]; 49(5):741-747. Disponível em:

http:// www.scielo.br/scielo.php?pid=S008062342015000500741\&script=sci_arttext\& tlng=pt2

8. Silva RA, Vieira CX, Nery AA, Abreu FS, Silva NA, Jesus LR. Mortalidade por causas externas em jovens no estado da Bahia. Revista de Pesquisa: Cuidado é Fundamental Online [Internet]. 2018 [acesso em 2019 Set 23]; 10(1):46-51. Disponível em:http:/ / www.seer.unirio.br/index.php/cuidadofundamental/article/view/5975 /pdf_1.

9. Mesquita TM, Albuquerque RS, Bomfim AMA, Sales MLH, Santana MCCP, Ferreira AMV. Recurso educativo em primeiros socorros no processo ensinoaprendizagem em crianças de uma escola pública. Revista Ciência Plural [Internet]. 2017 [acesso em 2019 Jun 24]; 3(1): 35-50. Disponível em: https://periodicos.ufrn.br/rcp/article/view/11464/8587.

10. Galindo Neto NM, Caetano JÁ, Barros LM, Silva TM, Vasconcelos EMR. Primeiros socorros na escola: construção e validação de cartilha educativa para professores. Acta Paulista de Enfermagem [Internet]. 2017 [acesso em 2019 Jun 24]; 30(1):87-93. Disponível em: http:/ / www.scielo.br/pdf/ape/v30n1/1982-0194-ape30-01-0087.pdf.

11. Barbier R. A pesquisa-ação. Brasília, DF: Líber; 2007.

12. Gil AC. Como elaborar projetos de pesquisa. 5. ed. São Paulo: Atlas; 2010.

Ministério da Saúde, Conselho Nacional de Saúde. Resolução n ${ }^{\circ}$ 466, de 12 de zembro de 2012: diretrizes e normas regulamentadoras de pesquisas envolvendo res humanos. Diário Oficial da União; Brasília, 13 Jun 2013.

Neto JAC, Brum IV, Pereira DR, Santos LG, Moraes SL, Ferreira RE. Suporte sico de vida entre leigos. International Journal of Cardiovascular Sciences 
[Internet]. 2016 [acesso em 2019 Set 10]; 29(6):443-452. Disponível em: http:/ / www.onlineijcs.org/sumario/29/pdf/v29n6a04.pdf.

15. Albuquerque AM, Gouveia BLA, Lopes CAA, Ferreira JA, Pinto MB, Santos NCCB. Salvando vidas: avaliando o conhecimento de adolescentes de uma escola pública sobre primeiros socorros. Revista de Enfermagem UFPE Online [Internet]. 2015 [acesso em 2020 Abr 05]; 1(9):32-38. Disponível em:

https://periodicos.ufpe.br/revistas/revistaenfermagem/article/view/10303/10969.

\section{Dantas RAN, Dantas DV, Silva IRN, Araújo NM, Laurentino AMA, Nunes}

HMA. Abordagem dos primeiros socorros na escola: crianças, adolescentes e professores aprendendo a salvar vidas. Enfermagem Brasil [Internet]; 2018 [acesso em 2020 Abr 03]; 3(17):259-265. Disponível em:

https:/ / portalatlanticaeditora.com.br/index.php/enfermagembrasil/article/view/1 186/3753.

17. Silva KVLG, Gonçalves GAA, Santos SB, Machado MFAS, Rebouças CBA, Silva VM, et al. Training of adolescent multipliers from the perspective of health promotion core competencies. Revista Brasileira de Enfermagem [Internet]. 2018 [acesso em 2019 Ago 23]; 71(1):89-96. Disponível em:

http:/ / www.scielo.br/scielo.php?script=sci_arttext\&pid=S003471672018000100089\& lng=en\&tlng=en.

18. Casemiro JP, Fonseca ABC, Secco FVM. Promover saúde na escola: reflexões a partir de uma revisão sobre saúde escolar na América Latina. Ciência \& Saúde Coletiva [Internert]. 2014 [acesso em 2019 Out 22];19(3):829-840. Disponível em: http:/ / www.scielo.br/pdf/csc/v19n3/1413-8123-csc-19-03-00829.pdf.

19. Fernandes JMG, Leite ALS, Auto BAD, Lima JEG, Rivera IR, Mendonça MA. Ensino de suporte básico de vida para alunos de escolas pública e privada do ensino médio. Arq. Bra. Cardiol. [Internet]. 2014 [acesso em 2019 Out 10]; 102(6):593-601. Disponível em:

http:/ / www.scielo.br/scielo.php?script=sci_arttext\&pid=S006682X2014000600010\&l $\mathrm{ng}=\mathrm{en} \& \mathrm{nrm}=\mathrm{iso} \& \mathrm{tlng}=\mathrm{pt}$.

20. Coelho JPSL. Ensino de primeiros socorros nas escolas e sua eficácia. Revista Científica do ITPAC [Internet]. 2015 [acesso em 2019 Set 10]; 8(1):7. Disponível em: https://assets.itpac.br/arquivos/coppex/revista\%20volume\%208/artigo7.pdf.

21. Bertoldo CS, Wickert DC, Maciel VQS, Piccin C, Silva JL, Munhoz OL, et al. oções básicas de primeiros socorros: relato de experiência de um projeto de tensão rural.: relato de experiência de um projeto de extensão rural. Revista rasileira em Promoção da Saúde [Internet]. 2019 [acesso em 2020 Abr 02]; 32(1):10. isponível em: https:/ / periodicos.unifor.br/RBPS/article/view/8255. 